\title{
Daily Usage of Proton Pump Inhibitors May Reduce the Severity of Critical Upper Gastrointestinal Bleeding in Elderly Patients
}

\author{
Hidetaka Matsuda, Takuto Nosaka, Yu Akazawa, Yasushi Saito, Yoshihiko Ozaki, \\ Kazuto Takahashi, Tatsushi Naito, Kazuya Ofuji, Masahiro Ohtani, Katsushi Hiramatsu, \\ and Yasunari Nakamoto
}

Second Department of Internal Medicine, Faculty of Medical Sciences, University of Fukui, Fukui, Japan

Correspondence should be addressed to Yasunari Nakamoto; nakamoto-med2@med.u-fukui.ac.jp

Received 17 May 2020; Accepted 20 July 2020; Published 6 August 2020

Academic Editor: Eiji Sakai

Copyright (c) 2020 Hidetaka Matsuda et al. This is an open access article distributed under the Creative Commons Attribution License, which permits unrestricted use, distribution, and reproduction in any medium, provided the original work is properly cited.

Introduction. We retrospectively examined the relationship between daily proton pump inhibitor (PPI) use and severity of upper gastrointestinal bleeding (UGIB), mainly in the elderly. Methods. We included 97 patients with nonvariceal UGIB diagnosed at our hospital from January 2012 to October 2017. Bleeding severity was assessed using the shock index (SI) and estimated bleeding volume; 49 patients met the criterion for the mild group and 48 for the moderate/severe group. The effect of PPI use on bleeding severity was compared between the groups. The relationships of PPI use and dose with the clinical symptoms of UGIB were also analyzed. Results. Among the 97 patients, 17 (17.5\%) habitually used PPIs. The rate of habitual PPI use was significantly higher in the mild group, indicating as an independent factor contributing to a reduction in the severity of UGIB in a multiple logistic regression analysis (30.6\% vs. 4.2\%; OR 10.147; 95\% CI 2.174-47.358, $P<0.01)$. When analyzing data for a subgroup of patients older than 75 years, we found the protective PPI effect to be even higher in the mild UGIB group than in the moderate/severe group (37.0\% vs. 5.6\%; OR 10.000; 95\% CI 1.150-86.951, $P<0.05)$. Conversely, we found no association between PPI prescription and UGIB symptoms in patients younger than 75 years. The mean estimated bleeding volume and SI in the 17 habitual PPI users were both significantly less than those among the 80 nonhabitual users, respectively $(P<0.05)$. The proportion of patients with mild UGIB was similar between the low- and high-dose PPI users. Conclusions. Particularly in elderly patients with nonvariceal UGIB, habitual PPI use can alleviate the clinical symptoms of UGIB by suppressing the volume of bleeding, regardless of the adapted dose of PPIs.

\section{Introduction}

Upper gastrointestinal bleeding (UGIB) is a serious condition that can take a severe course $[1,2]$. UGIB can be fatal, particularly in elderly patients, whose physical strength has declined over time and who have various underlying diseases [3-7]. Currently, populations, primarily in developed countries, are rapidly aging [8], and even in Japan, elderly individuals over the age of 75 , comprise approximately $15 \%$ of the total population [9]. Therefore, treating UGIB is an important issue that needs to be incorporated into routine medical care, especially among elderly patients [5]. Habitual proton pump inhibitor (PPI) use is known to decrease the incidence rate of UGIB among individuals taking drugs that might induce UGIB (e.g., nonsteroidal anti-inflammatory drugs [NSAIDs], antiplatelet drugs, anticoagulants) $[10,11]$. Additionally, the inhibitory effect of these PPIs on UGIB incidence has been reported to be more effective in elderly populations than in others $[12,13]$. However, to what extent habitual PPI use influences clinical UGIB symptoms and severity remains unclear. In the present retrospective study, we investigated the influence of habitual PPI use on clinical symptoms and bleeding severity (determined by the shock index (SI) and estimated bleeding volume) in nonvariceal UGIB cases, taking 
miscellaneous patient characteristics such as age into account, to formulate countermeasures for UGIB in an aging society.

\section{Methods}

2.1. Subjects. We retrospectively analyzed anonymous clinical data of 97 patients with nonvariceal UGIB diagnosed by upper gastrointestinal endoscopy at our hospital from January 2012 to October 2017 (mean age $71.6 \pm 1.3$ years, males/females: $62 / 35$ cases). All patients (or their parents or guardians) had agreed to the treatment of UGIB by providing written informed consent. This study was performed in compliance with relevant laws and institutional guidelines and following the ethical standards of the Declaration of Helsinki. This study was approved by the institutional review board (IRB) of the University of Fukui (IRB number: 20170132). In this study, no additional intervention was conducted on the subjects, and informed consent was obtained in the form of opt-out on the website of the University of Fukui Hospital (http:// research.hosp.u-fukui.ac.jp/rinsho/).

2.2. Definition of Upper Gastrointestinal Bleeding. Using the review of Kamboj et al. [2] as a reference, UGIB was defined as bleeding caused by benign/malignant diseases (ulcers, solid cancers, vascular abnormalities, etc.) in the esophagus, stomach, and duodenum.

2.3. Determination of Upper Gastrointestinal Bleeding Severity. The estimated bleeding volume and SI were used as parameters to determine the bleeding severity in each UGIB case. Using the hemoglobin values recorded on the patients' medical records before bleeding and at the time of UGIB diagnosis, we calculated each patient's estimated bleeding volume using Nadler's equation, which can enable assessment of the individual's total blood volume [14]. The SI was calculated by dividing the heart rate by the systolic blood pressure [15].

Using the bleeding severity classifications of the American College of Surgeons and other reports that investigated the cut-off value of the SI in UGIB cases as references [16-18], the present study classified bleeding severity as follows: mild: estimated bleeding volume $<1,000 \mathrm{~mL}$ and SI $<1.0$; moderate: estimated bleeding volume $1000-2000 \mathrm{~mL}$ or SI 1.0-2.0; severe: estimated bleeding volume $>2000 \mathrm{~mL}$ or $\mathrm{SI}>2.0$.

2.4. Patient Classification and Analysis Categories. Of the total 97 cases, 49 were classified as mild cases, and 48 were classified as moderate/severe cases according to bleeding severity. The effect of PPI use on bleeding severity was compared and analyzed between the groups, along with the lesions responsible for the bleeding, underlying diseases exacerbated by aging, and patient characteristics selected as risk factors for UGIB (age, sex, underlying disease [hypertension/diabetes/dyslipidemia/cerebrovascular disease/heart disease/hepatic cirrhosis/kidney disease/dementia/extra-gastrointestinal malignant tumors], antithrombotic drugs [antithrombotic drugs/anticoagulants], NSAID use) [1, 2, 7, 19-21]. Additionally, correlations between PPI use/dose and clinical UGIB symptoms (estimated blood volume, SI, total transferred blood volume) were also analyzed.
2.5. Statistical Analysis. GraphPad Prism ver. 6.0 (GraphPad Software, Inc., La Jolla, CA, USA) and SPSS Statistics ver. 20 (SPSS Inc., Chicago, IL, USA) were used for statistical analysis. Associations between the severity of UGIB and the clinical characteristics (including the daily usage and administered dose of PPI) of subjects were examined using Fisher's exact probability test for univariate analysis and multivariable logistic regression for multivariable analysis. Welch's $t$-test was used for comparing clinical UGIB symptoms (estimated bleeding volume, SI, total transferred blood volume) between PPI users, and nonusers. $P<0.05$ was considered significant.

\section{Results}

Results of subject characteristic influences on UGIB severity are shown in Table 1(a). Mean ages in both mild and moderate/severe cases were high, at $72.3 \pm 12.2$ and $69.9 \pm 13.6$ years, respectively, with no statistically significant differences between the two groups. There was also no difference between the groups in terms of sex and the compositional ratio of diseases causing UGIB. Most patients had some form of underlying disease (mild group: $81.6 \%$, moderate/severe group: $79.2 \%, P>0.05)$. Among all subjects, $17.5 \%$ (17/97) used PPI. Habitual PPI use in the mild group (30.6\%) was statistically significantly higher $(P<0.01)$ than that in the moderate/severe group (4.2\%), and the multiple logistic regression analysis showed that habitual PPI use is a contributing factor to decreased bleeding severity (odds ratio $[\mathrm{OR}]$ : $10.147,95 \%$ confidence interval [CI] $2.174-$ 47.358, $P<0.01)$. PPIs were administered in seven cases to prevent the recurrence of peptic ulcer disease, in five cases for combined usage with antithrombotic drugs, in four cases for gastroesophageal reflux disease (GERD), and in one case for gastric cancer. Of those 17 cases, 11 showed concordance between the targeted lesion for PPI administration and the source of bleeding. In terms of the duration of PPI usage, there was no difference between the two groups (proportion of $>6$ months duration $11 / 15$ vs. $2 / 2$ ). Correlations between other habitually used drugs and bleeding severity were also analyzed in the present study. No statistically significant differences were observed in $\mathrm{H}_{2}$ receptor blocker use between the two groups. Additionally, no statistically significant influence of habitual antiplatelet drug and anticoagulant use, including its complications, was observed on bleeding severity. There was also no difference in Helicobacter pylori (H. pylori) infection rate between the two groups, $59.3 \%$ of the mild group vs. $70.0 \%$ of the moderate/severe group.

Subjects were classified into two groups (above and below 75 years old), and factors relating to nonvariceal UGIB severity were investigated in each group (Tables 1(b) and 1(c)). Habitual PPI use in the mild group over the age of 75 $(37.0 \%)$ was statistically significantly higher $(P<0.05)$ than that in the moderate/severe group (5.6\%), and habitual PPI use in elderly individuals was determined as a factor contributing to decreased UGIB severity (OR: 10.000; 95\% CI 1.15086.951, $P<0.05)$. Habitual PPI use in the mild group under the age of 75 also showed higher tendencies than that in the moderate/severe group, but no statistically significant differences were observed $(22.7 \%$ vs. $3.3 \%, P>0.05)$. The present 
TABLE 1: Comparison of the clinical characteristics between the two groups of patients with different severities of upper gastrointestinal bleeding.

(a) Clinical characteristics of all 97 patients enrolled in this study

\begin{tabular}{|c|c|c|c|c|c|}
\hline \multirow[b]{2}{*}{ Characteristics } & \multicolumn{2}{|c|}{ Bleeding severity } & \multirow[b]{2}{*}{$\begin{array}{l}\text { Univariate } \\
P \text { value }\end{array}$} & \multicolumn{2}{|c|}{ Multivariate } \\
\hline & $\begin{array}{c}\text { Mild } \\
n=49(\%)\end{array}$ & $\begin{array}{c}\text { Moderate/severe } \\
n=48(\%)\end{array}$ & & OR $(95 \% \mathrm{CI})$ & $\begin{array}{c}P \\
\text { value }\end{array}$ \\
\hline Age & $72.3 \pm 12.2$ & $69.9 \pm 13.6$ & 0.2174 & - & n.s. \\
\hline Male & $31(63.3)$ & $31(64.6)$ & 1.0000 & & \\
\hline \multicolumn{6}{|l|}{ Etiology of bleeding } \\
\hline Esophageal ulcer & $2(4.1)$ & $2(4.2)$ & 1.0000 & & \\
\hline Gastric ulcer & $22(44.9)$ & $30(62.5)$ & 0.1044 & - & n.s. \\
\hline Duodenal ulcer & $11(22.4)$ & $8(16.7)$ & 0.6102 & & \\
\hline Solid cancer & $5(10.2)$ & $1(2.1)$ & 0.2041 & - & n.s. \\
\hline $\begin{array}{l}\text { Others (Mallory-Weiss, } \\
\text { esophagitis, angiodysplasia, etc.) }\end{array}$ & $9(18.4)$ & $7(14.6)$ & 0.7854 & & \\
\hline \multicolumn{6}{|l|}{ Medications } \\
\hline Antiplatelets & $7(14.3)$ & $6(12.5)$ & 1.0000 & & \\
\hline Anticoagulants & $4(8.2)$ & $4(8.3)$ & 1.0000 & & \\
\hline NSAIDs & $7(14.3)$ & $8(16.7)$ & 0.7854 & & \\
\hline Proton pump inhibitor & $15(30.6)$ & $2(4.2)$ & 0.0009 & $\begin{array}{c}10.147 \\
(2.174-47.358)\end{array}$ & 0.003 \\
\hline $\mathrm{H}_{2}$ receptor blocker & $3(6.1)$ & $5(10.4)$ & 0.4865 & & \\
\hline \multicolumn{6}{|l|}{ Comorbid illness } \\
\hline Hypertension & $26(53.1)$ & $20(41.7)$ & 0.3115 & & \\
\hline Diabetes mellitus & $10(20.4)$ & $11(22.9)$ & 0.8092 & & \\
\hline Hyperlipidemia & $7(14.3)$ & $7(14.6)$ & 1.0000 & & \\
\hline Cerebrovascular diseases & $5(10.2)$ & $7(14.6)$ & 0.5529 & & \\
\hline Cardiovascular diseases & $9(18.4)$ & $5(10.4)$ & 0.3873 & & \\
\hline Liver diseases & $2(4.1)$ & $6(12.5)$ & 0.1591 & - & n.s. \\
\hline Renal diseases & $6(12.2)$ & $3(6.3)$ & 0.4865 & & \\
\hline Dementia & $2(4.1)$ & $2(4.2)$ & 1.0000 & & \\
\hline $\begin{array}{l}\text { Nongastrointestinal } \\
\text { malignancies }\end{array}$ & $9(18.4)$ & $10(20.8)$ & 0.8026 & & \\
\hline
\end{tabular}

(b) Clinical characteristics of 45 patients over 75 years old enrolled in this study

\begin{tabular}{|c|c|c|c|c|c|}
\hline \multirow[b]{2}{*}{ Characteristics } & \multicolumn{2}{|c|}{ Bleeding severity } & \multirow{2}{*}{$\begin{array}{l}\text { Univariate } \\
P \text { value }\end{array}$} & \multicolumn{2}{|c|}{ Multivariate } \\
\hline & $\begin{array}{c}\text { Mild } \\
n=27(\%)\end{array}$ & $\begin{array}{c}\text { Moderate/severe } \\
n=18(\%)\end{array}$ & & OR (95\% CI) & $\begin{array}{c}P \\
\text { value }\end{array}$ \\
\hline Age & $82.3 \pm 1.0$ & $82.2 \pm 1.3$ & 0.9587 & & \\
\hline Male & $15(55.6)$ & $11(61.1)$ & 0.7660 & & \\
\hline \multicolumn{6}{|l|}{ Etiology of bleeding } \\
\hline Esophageal ulcer & $2(7.4)$ & $0(0.0)$ & 0.5091 & & \\
\hline Gastric ulcer & $10(37.0)$ & $11(61.1)$ & 0.1376 & - & n.s. \\
\hline Duodenal ulcer & $5(18.5)$ & $2(11.1)$ & 0.6844 & & \\
\hline Solid cancer & $5(18.5)$ & $1(5.6)$ & 0.3773 & & \\
\hline $\begin{array}{l}\text { Others (Mallory-Weiss, } \\
\text { esophagitis, angiodysplasia, etc.) }\end{array}$ & $5(18.5)$ & $4(22.2)$ & 1.0000 & & \\
\hline \multicolumn{6}{|l|}{ Medications } \\
\hline Antiplatelets & $6(22.2)$ & $4(22.2)$ & 1.0000 & & \\
\hline Anticoagulants & $3(11.1)$ & $3(16.7)$ & 0.6703 & & \\
\hline NSAIDs & $5(18.5)$ & $2(11.1)$ & 0.6844 & & \\
\hline
\end{tabular}


TABLE 1: Continued.

\begin{tabular}{|c|c|c|c|c|c|}
\hline \multirow[b]{2}{*}{ Characteristics } & \multicolumn{2}{|c|}{ Bleeding severity } & \multirow[b]{2}{*}{$\begin{array}{l}\text { Univariate } \\
P \text { value }\end{array}$} & \multicolumn{2}{|c|}{ Multivariate } \\
\hline & $\begin{array}{c}\text { Mild } \\
n=27(\%)\end{array}$ & $\begin{array}{c}\text { Moderate/severe } \\
n=18(\%)\end{array}$ & & OR (95\% CI) & $\begin{array}{c}P \\
\text { value }\end{array}$ \\
\hline Proton pump inhibitor & $10(37.0)$ & $1(5.6)$ & 0.0307 & $\begin{array}{c}10.000 \\
(1.150-8951)\end{array}$ & 0.037 \\
\hline $\mathrm{H}_{2}$ receptor blocker & $3(11.1)$ & $3(16.7)$ & 0.6703 & & \\
\hline \multicolumn{6}{|l|}{ Comorbid illness } \\
\hline Hypertension & $19(70.4)$ & $12(66.7)$ & 0.7668 & & \\
\hline Diabetes mellitus & $6(22.2)$ & $7(38.9)$ & 0.3172 & & \\
\hline Hyperlipidemia & $5(18.5)$ & $5(27.8)$ & 1.0000 & & \\
\hline Cerebrovascular diseases & $5(18.5)$ & $3(16.7)$ & 1.0000 & & \\
\hline Cardiovascular diseases & $7(25.9)$ & $3(16.7)$ & 0.7161 & & \\
\hline Liver diseases & $2(7.4)$ & $1(5.6)$ & 1.0000 & & \\
\hline Renal diseases & $5(18.5)$ & $2(11.1)$ & 0.6844 & & \\
\hline Dementia & $2(7.4)$ & $1(5.6)$ & 1.0000 & & \\
\hline $\begin{array}{l}\text { Nongastrointestinal } \\
\text { malignancies }\end{array}$ & $3(11.1)$ & $4(22.2)$ & 0.4122 & & \\
\hline
\end{tabular}

(c) Clinical characteristics of 52 patients younger than 75 years old enrolled in this study

\begin{tabular}{|c|c|c|c|c|c|}
\hline \multirow[b]{2}{*}{ Characteristics } & \multicolumn{2}{|c|}{ Bleeding severity } & \multirow{2}{*}{$\begin{array}{l}\text { Univariate } \\
P \text { value }\end{array}$} & \multicolumn{2}{|c|}{ Multivariate } \\
\hline & $\begin{array}{c}\text { Mild } \\
n=22(\%)\end{array}$ & $\begin{array}{c}\text { Moderate/severe } \\
n=30(\%)\end{array}$ & & OR $(95 \% \mathrm{CI})$ & $\begin{array}{c}P \\
\text { value }\end{array}$ \\
\hline Age & $62.1 \pm 1.8$ & $62.5 \pm 2.1$ & 0.4869 & & \\
\hline Male & $16(72.7)$ & $20(66.7)$ & 0.7646 & & \\
\hline \multicolumn{6}{|l|}{ Etiology of bleeding } \\
\hline Esophageal ulcer & $0(0.0)$ & $2(6.7)$ & 0.5023 & & \\
\hline Gastric ulcer & $12(54.5)$ & $19(63.3)$ & 0.5764 & & \\
\hline Duodenal ulcer & $6(27.2)$ & $6(20.0)$ & 0.7402 & & \\
\hline Solid cancer & $0(0.0)$ & $0(0.0)$ & 1.0000 & & \\
\hline $\begin{array}{l}\text { Others (Mallory-Weiss, } \\
\text { esophagitis, angiodysplasia, etc.) }\end{array}$ & $4(18.2)$ & $3(10.0)$ & 0.4385 & & \\
\hline \multicolumn{6}{|l|}{ Medications } \\
\hline Antiplatelets & $1(4.5)$ & $2(6.7)$ & 1.0000 & & \\
\hline Anticoagulants & $1(4.5)$ & $1(3.3)$ & 1.0000 & & \\
\hline NSAIDs & $2(9.1)$ & $6(20.0)$ & 0.4420 & & \\
\hline Proton pump inhibitor & $5(22.7)$ & $1(3.3)$ & 0.0716 & - & n.s. \\
\hline $\mathrm{H}_{2}$ receptor blocker & $0(0.0)$ & $2(6.7)$ & 0.5023 & & \\
\hline \multicolumn{6}{|l|}{ Comorbid illness } \\
\hline Hypertension & $7(31.8)$ & $8(26.7)$ & 0.7618 & & \\
\hline Diabetes mellitus & $4(18.2)$ & $4(13.3)$ & 0.7084 & & \\
\hline Hyperlipidemia & $2(9.1)$ & $2(6.7)$ & 1.0000 & & \\
\hline Cerebrovascular diseases & $0(0.0)$ & $4(13.3)$ & 0.1282 & - & n.s. \\
\hline Cardiovascular diseases & $2(9.1)$ & $2(6.7)$ & 1.0000 & & \\
\hline Liver diseases & $2(9.1)$ & $3(10.0)$ & 1.0000 & & \\
\hline Renal diseases & $3(13.6)$ & $3(6.3)$ & 0.6890 & & \\
\hline Dementia & $0(0.0)$ & $1(3.3)$ & 1.0000 & & \\
\hline $\begin{array}{l}\text { Nongastrointestinal } \\
\text { malignancies }\end{array}$ & $2(9.1)$ & $7(23.3)$ & 0.2720 & & \\
\hline
\end{tabular}

Values were estimated by Fisher's exact probability test for univariate analysis, and multivariable logistic regression for multivariable analysis. NSAIDs: nonsteroidal anti-inflammatory drugs. 
study did not identify other factors relating to bleeding severity in either the elderly (over 75 years) and younger (under 75 years) groups.

The influence of habitual PPI use on clinical manifestations of nonvariceal UGIB was investigated (Figure 1). The average estimated bleeding volume in the 17 subjects who habitually used PPI was $591 \pm 109.1 \mathrm{~mL}$, which was statistically significantly less $(P<0.05)$ than that in the nonhabitual users, at $944 \pm 62.6 \mathrm{~mL}$. Additionally, the average value of the SI at the time of bleeding in habitual PPI users was statistically significantly lower than that in nonhabitual PPI users $(0.73 \pm 0.27$ vs. $0.98 \pm 0.49, P<0.05)$. Meanwhile, the average volume of packed red blood cell volume transfused while being hospitalized was lower in habitual PPI users than in nonhabitual users, but no statistically significant differences were observed $(477.6 \pm 566.7 \mathrm{~mL}$ vs. 672.0 $\pm 100.9 \mathrm{~mL}, P>0.05$ ).

Finally, correlations between PPI dose and UGIB severity in the 17 habitual PPI users are shown in Figure 2. Of the seven patients who took a maintenance PPI dose (omeprazole/rabeprazole/esomeprazole: $10 \mathrm{mg} /$ day, lansoprazole: $15 \mathrm{mg} /$ day) before bleeding, $85.7 \%$ were mild cases, and of the 10 patients who took a high PPI dose (omeprazole/rabeprazole/esomeprazole: $20 \mathrm{mg}$ /day, lansoprazole: $30 \mathrm{mg} /$ day), $90.0 \%$ were mild cases; no statistically significant differences were observed $(P>0.05)$.

\section{Discussion}

In this retrospective analysis, daily usage of PPI was proved to reduce the severity of UGIB, especially in patients older than 75 years old.

PPI inhibits gastric acid secretion and serves as a mucosal treatment for reflux esophagitis and peptic ulcer cases that cause UGIB [22-24]. PPI administration is known to reduce UGIB incidence rates in high-risk UGIB cases $[10,11]$, and reports have indicated that its preventative effects are particularly high in elderly individuals $[12,13]$. However, the extent to which PPI contributes to UGIB severity is unclear. In the present study, we investigated nonvariceal UGIB cases in our hospital and correlations between habitual PPI use and UGIB severity, as well as age and other clinical characteristics.

The bleeding severity of each enrolled subject was determined based on the estimated bleeding volume and SI, and multivariate analysis was used to compare clinical characteristics between mild and moderate/severe cases. Results showed that PPI use is an independent factor that reduces UGIB severity, with a similar effect observed in the case group over the age of 75. In patients under the age of 75, a higher frequency of habitual PPI users was observed in the mild bleeding group than in the moderate/severe group, although the difference did not reach statistical significance. Recently, Li et al. [4] conducted a prospective study that included patients in whom antiplatelet drugs were administered as secondary prevention against the development of cardiovascular events, and they reported that the numbers needed to treat for concomitant PPI use in the prevention of severe UGIB is low in subjects over the age of 75 . Results from the present study and those of Li et al. [4] indicate that habitual PPI use in elderly individ- uals can prevent a worsening general condition that accompanies gastrointestinal bleeding. As far as we know, the present study is the first report that investigated correlations between PPI and UGIB severity.

The present study used the SI and estimated blood volume to investigate the influence of habitual PPI use on UGIB severity. Results showed that PPI users had statistically significantly lower SI and estimated blood volume than nonusers. These results indicate that habitual PPI use can reduce the bleeding severity in UGIB cases by inhibiting total bleeding volume. The Rockall, AIMS65, and Glasgow-Blatchford scores have been reported as useful preendoscopic risk assessment tools $[1,25]$. Meanwhile, these require biochemical blood examination results, and calculations are rather complex.

In comparison, SI calculation is simple and suitably reflects circulatory dynamics, with reports indicating that it has a practical use for UGIB identical to that of other scoring methods $[15,26]$. The present analysis used the SI and estimated bleeding volume to investigate direct correlations between PPI and blood loss caused by UGIB. Among the 46 patients with hypertension in our present study, only one was using beta-blockers. Thus, we believe that the SI was not influenced by beta-blocker usage in our study and was, therefore, not underestimated.

Reports have indicated that controlling transferred blood volume can result in the reduction of early death and rebleeding rates in acute UGIB cases [27]. For this reason, it is recommended that the hemoglobin threshold be maintained at 70-80 g/L for UGIB cases [1]. The present investigation did not show statistically significant differences in PPI use concerning the total transferred blood volume related to UGIB. This may have been partly due to appropriate blood transfusion measures by the primary physicians following diagnoses of individual subjects, to some extent.

Some issues must be addressed if the present results are to be applied in the clinical setting. First, we must consider which cases primarily among elderly individuals are suitable for habitual PPI use. As mentioned previously, the elderly population is currently increasing, and administering PPI to all elderly individuals over the age of 75 is not practical. Guidelines recommend maintenance PPI administration for patients with GERD accompanied by sores and high relapse rates of peptic ulcers (e.g., NSAIDs, low-dose aspirin administration cases, cases without $H$. pylori eradication treatment) $[24,28]$. It is predicted that PPI use in these types of cases would result in not only the reduction of gastrointestinal bleeding frequency but also bleeding severity. Meanwhile, the extent to which habitual PPI use should be indicated for cases besides these is still up for debate. In this study, 17 patients suffered from UGIB despite the daily usage of PPI. Of note, however, was that the bleeding severity was mild in 15 of the 17 patients. Future studies are required to clarify the characteristics of patients with an extremely high risk of UGIB, such as older adult patients. Habitual PPI usage in such patients can potentially minimize the harmful effects of UGIB.

The next issue involves considering adverse events accompanying long-term PPI administration. Correlation of long-term PPI administration with various adverse events including osteoporosis-related bone fracture, Clostridium 


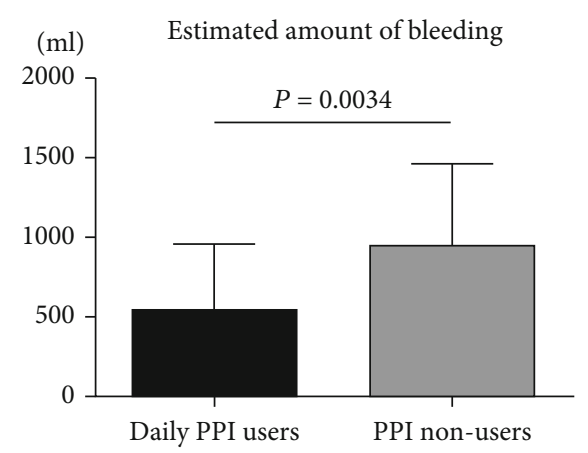

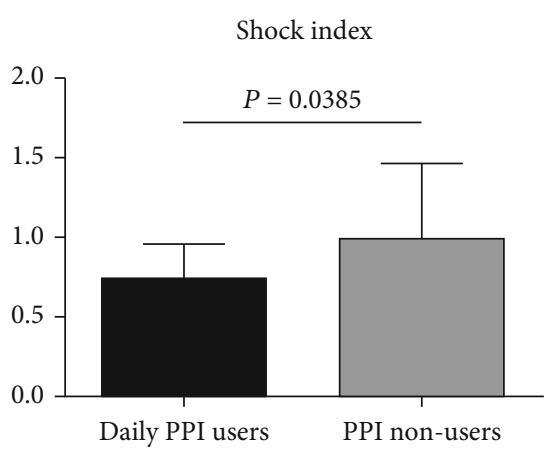

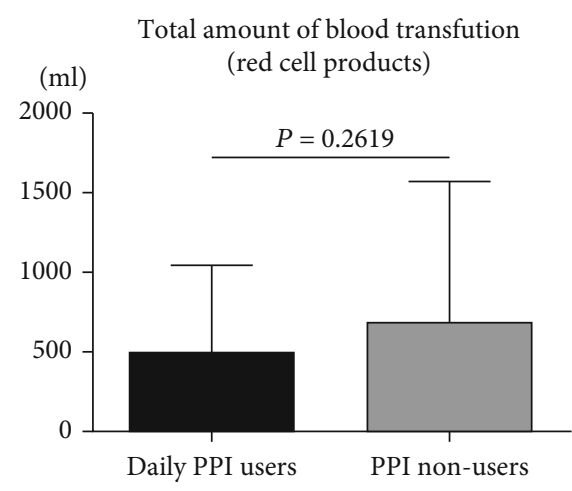

Welch's $t$ test

Figure 1: Comparisons of the clinical manifestation of upper gastrointestinal bleeding (estimated amount of bleeding, shock index, and total amount of blood transfusion) between 17 patients with and 80 patients without daily usage of proton pump inhibitors (PPIs). The mean estimated bleeding volume and SI in the habitual PPI users were both significantly less than those among the non-habitual users, respectively $(P<0.05)$. Meanwhile, there was no significant difference in the average volume of packed red blood cell volume transfused while being hospitalized between patients' groups of habitual or nonhabitual PPI users $(P>0.05)$.

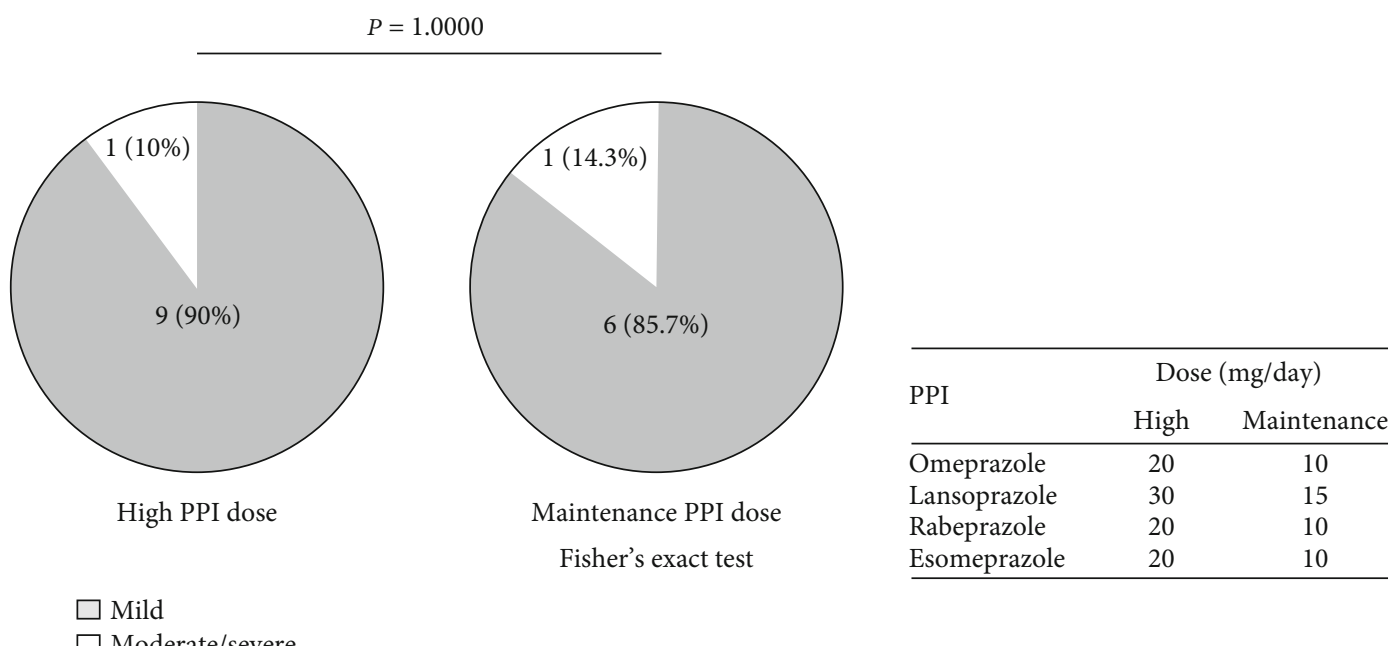

FIGURE 2: Comparisons of the frequencies of nonvariceal upper gastrointestinal bleeding (UGIB) between 10 patients with high-dose and seven patients with maintenance dose of daily proton pump inhibitor (PPI) consumption. The proportion of patients with mild UGIB was similar between the low- and high-dose PPI users.

difficile infection, pneumonia, vitamin B12 deficiency, kidney disease, and dementia has been previously reported, although the findings are controversial [29-32]. In an expert review published by the American Gastroenterological Association, the benefits of appropriate PPI prescriptions are thought to outweigh their risks; the authors add that there is insufficient evidence to recommend specific strategies for mitigating the adverse effects of PPI usage, including long-term PPI usage [31]. Nevertheless, maintenance with the minimum dose necessary is recommended when administering PPI over a long period, especially in older adults $[24,29,31]$. The present results, which showed that habitual PPI use at a maintenance dose resulted in decreases in UGIB severity, will pave the way for the development of PPI administration methods that minimize adverse event risks without negatively affecting the patient's quality of life.

The mechanisms by which habitual PPI use reduced both the incidence and severity of UGIB should be investi- gated further. PPI has been shown to reduce the severity of gastrointestinal mucosal injury by suppressing gastric acid secretion [33]. In addition, since most UGIB is caused by damage of the gastrointestinal mucosa [2], it is expected that the severity of UGIB will be reduced in habitual PPI users, most likely due to constant suppression of gastric acid secretion $[34,35]$.

\section{Conclusions}

Habitual PPI use was shown to diminish clinical symptoms by reducing bleeding volume in nonvariceal UGIB cases, particularly among elderly individuals. Additionally, even low doses of habitual PPI were shown to possibly reduce UGIB severity. Further investigations are required to establish a suitable PPI administration method to alleviate UGIB symptoms in elderly individuals. 


\section{Data Availability}

The data used to support the findings of this study are available from the corresponding author $\mathrm{YN}$ on request.

\section{Conflicts of Interest}

The authors state that they have no conflicts of interest and no financial relationships relevant to this publication.

\section{Acknowledgments}

We would like to thank Editage (https://www.editage.com) for English language editing.

\section{References}

[1] A. J. Stanley and L. Laine, "Management of acute upper gastrointestinal bleeding," BMJ, vol. 364, 2019.

[2] A. K. Kamboj, P. Hoversten, and C. L. Leggett, "Upper gastrointestinal bleeding: etiologies and management," Mayo Clinic Proceedings, vol. 94, no. 4, pp. 697-703, 2019.

[3] G. F. Longstreth, "Epidemiology of hospitalization for acute upper gastrointestinal hemorrhage: a population-based study," The American Journal of Gastroenterology, vol. 90, no. 2, pp. 206-210, 1995.

[4] L. Li, O. C. Geraghty, Z. Mehta, P. M. Rothwell, and Oxford Vascular Study, "Age-specific risks, severity, time course, and outcome of bleeding on long- term antiplatelet treatment after vascular events: a population-based cohort study," Lancet, vol. 390, no. 10093, pp. 490-499, 2017.

[5] D. Kozieł, J. Matykiewicz, and S. Głuszek, "Gastrointestinal bleeding in patients aged 85 years and older," Polish Journal of Surgery, vol. 83, no. 11, pp. 606-613, 2011.

[6] S. Christensen, A. Riis, M. Nørgaard, H. T. Sørensen, and R. W. Thomsen, "Short-term mortality after perforated or bleeding peptic ulcer among elderly patients: a populationbased cohort study," BMC Geriatrics, vol. 7, no. 1, 2007.

[7] J. M. Watters, "Surgery in the elderly," Canadian Journal of Surgery, vol. 45, no. 2, pp. 104-108, 2002.

[8] United Nations, Department of Economic and Social Affairs, Population Division, "World Population Ageing 2017 - Highlights (ST/ESA/SER.A/397),” 2017.

[9] Cabinet Office, Government of Japan, "Annual Report on the Ageing Society [Summary] FY 2019,” 2020, https://www8.cao .go.jp/kourei/english/annualreport/2019/pdf/2019.pdf.

[10] W. A. Ray, C. P. Chung, K. T. Murray et al., "Association of proton pump inhibitors with reduced risk of warfarin-related serious upper gastrointestinal bleeding," Gastroenterology, vol. 151, no. 6, pp. 1105-1112.e10, 2016.

[11] H. Yasuda, M. Yamada, S. Sawada et al., "Upper gastrointestinal bleeding in patients receiving dual antiplatelet therapy after coronary stenting," Internal Medicine, vol. 48, no. 19, pp. 1725-1730, 2009.

[12] W. A. Ray, C. P. Chung, K. T. Murray et al., "Association of oral anticoagulants and proton pump inhibitor cotherapy with hospitalization for upper gastrointestinal tract bleeding," Journal of the American Medical Association, vol. 320, no. 21, pp. 2221-2230, 2018.

[13] H. Fan, Z. Zheng, W. Feng et al., "Risk factors and prevention of upper gastrointestinal hemorrhage after a coronary artery bypass grafting operation," Surgery Today, vol. 40, no. 10, pp. 931-935, 2010.

[14] S. B. Nadler, J. H. Hidalgo, and T. Bloch, "Prediction of blood volume in normal human adults," Surgery, vol. 51, no. 2, pp. 224-232, 1962.

[15] A. Ratra, S. Rassameehiran, S. Parupudi, and K. Nugent, "Utility of the shock index and other risk-scoring tools in patients with gastrointestinal bleeding," Southern Medical Journal, vol. 109, no. 3, pp. 178-184, 2016.

[16] American College of Surgeons Committee on Trauma, Advanced Trauma Life Support (ATLS) Student Course Manual, American College of Surgeons, Chicago, 9th edition, 2012.

[17] F. Schulz, J. Hanusch, M. Starlinger, and R. Schiessel, "Significance of emergency endoscopy in severe upper gastrointestinal hemorrhage," Wiener Klinische Wochenschrift, vol. 98, no. 8, pp. 233-237, 1986.

[18] T. Mine, S. Murata, K. Nakazawa et al., "Glue embolization for gastroduodenal ulcer bleeding: contribution to hemodynamics and healing process," Acta Radiologica, vol. 54, no. 8, pp. 934938, 2013.

[19] N. L. de Groot, M. P. Hagenaars, H. M. Smeets, E. W. Steyerberg, P. D. Siersema, and M. G. H. van Oijen, "Primary non-variceal upper gastrointestinal bleeding in NSAID and low-dose aspirin users: development and validation of risk scores for either medication in two large Dutch cohorts," Journal of Gastroenterology, vol. 49, no. 2, pp. 245-253, 2014.

[20] S. A. Gale, D. Acar, and K. R. Daffner, "Dementia," The American Journal of Medicine, vol. 131, no. 10, pp. 1161-1169, 2018.

[21] Y. Tang, J. Shen, F. Zhang, X. Zhou, Z. Tang, and T. You, "Scoring systems used to predict mortality in patients with acute upper gastrointestinal bleeding in the ED," The American Journal of Emergency Medicine, vol. 36, no. 1, pp. 27-32, 2018.

[22] G. Brunner and W. Creutzfeldt, "Omeprazole in the long-term management of patients with acid-related diseases resistant to ranitidine," Scandinavian Journal of Gastroenterology, vol. 24, Supplement 166, pp. 101-105, 2009.

[23] B. Scally, J. R. Emberson, E. Spata et al., "Effects of gastroprotectant drugs for the prevention and treatment of peptic ulcer disease and its complications: a meta-analysis of randomised trials," The Lancet Gastroenterology \& Hepatology, vol. 3, no. 4, pp. 231-241, 2018.

[24] P. J. Kahrilas, N. J. Shaheen, M. F. Vaezi et al., “American Gastroenterological Association medical position statement on the management of gastroesophageal reflux disease," Gastroenterology, vol. 135, no. 4, pp. 1383-1391.e5, 2008.

[25] A. J. Stanley, L. Laine, H. R. Dalton et al., "Comparison of risk scoring systems for patients presenting with upper gastrointestinal bleeding: international multicentre prospective study," BMJ, vol. 356, article i6432, 2017.

[26] S. Rassameehiran, J. Teerakanok, S. Suchartlikitwong, and K. Nugent, "Utility of the shock index for risk stratification in patients with acute upper gastrointestinal bleeding," Southern Medical Journal, vol. 110, no. 11, pp. 738-743, 2017.

[27] C. Villanueva, A. Colomo, A. Bosch et al., "Transfusion strategies for acute upper gastrointestinal bleeding," The New England Journal of Medicine, vol. 368, no. 1, pp. 1121, 2013.

[28] K. Satoh, J. Yoshino, T. Akamatsu et al., "Evidence-based clinical practice guidelines for peptic ulcer disease 2015," Journal of Gastroenterology, vol. 51, no. 3, pp. 177-194, 2016. 
[29] M. L. Maes, D. R. Fixen, and S. A. Linnebur, "Adverse effects of proton-pump inhibitor use in older adults: a review of the evidence," Therapeutic Advances in Drug Safety, vol. 8, no. 9, pp. 273-297, 2017.

[30] M. F. Vaezi, Y. X. Yang, and C. W. Howden, "Complications of proton pump inhibitor therapy," Gastroenterology, vol. 153, no. 1, pp. 35-48, 2017.

[31] D. E. Freedberg, L. S. Kim, and Y. X. Yang, "The risks and benefits of long-term use of proton pump inhibitors: expert review and best practice advice from the American Gastroenterological Association," Gastroenterology, vol. 152, no. 4, pp. 706-715, 2017.

[32] J. E. Kurlander, J. K. Kennedy, J. H. Rubenstein et al., "Patients' perceptions of proton pump inhibitor risks and attempts at discontinuation: a national survey," The American Journal of Gastroenterology, vol. 114, no. 2, pp. 244-249, 2019.

[33] H. Fujisaki, H. Shibata, K. Oketani et al., "Effects of the proton pump inhibitor, E3810, on gastric secretion and gastric and duodenal ulcers or erosions in rats," Drug Investigation, vol. 3, no. 5, pp. 328-332, 1991.

[34] A. Schmassmann, "Mechanisms of ulcer healing and effects of nonsteroidal anti-inflammatory drugs," The American Journal of Medicine, vol. 104, no. 3, pp. 43S-51S, 1998.

[35] K. Andersson and E. Carlsson, "Potassium-competitive acid blockade: a new therapeutic strategy in acid-related diseases," Pharmacology \& Therapeutics, vol. 108, no. 3, pp. 294-307, 2005. 